\title{
Detection of aberrant methylated SEPT9 and NTRK3 genes in sporadic colorectal cancer patients as a potential diagnostic biomarker
}

\author{
SHAHIN BEHROUZ SHARIF ${ }^{1-3}$, SHAHRIAR HASHEMZADEH $^{4,5}$, REZA MOUSAVI ARDEHAIE $^{1,2}$, \\ AMIRTAHER EFTEKHARSADAT ${ }^{6}$, MORTAZA GHOJAZADEH ${ }^{7}$, AMIR HOSSEIN MEHRTASH ${ }^{2}$, \\ MEHRDAD ASGHARI ESTIAR $^{8}$, LADAN TEIMOORI-TOOLABI ${ }^{2}$ and EBRAHIM SAKHINIA ${ }^{1,5}$
}

\begin{abstract}
${ }^{1}$ Department of Biochemistry and Clinical Laboratory, Division of Medical Genetics, Faculty of Medicine, Tabriz University of Medical Sciences, Tabriz 5165665811; ${ }^{2}$ Department of Molecular Medicine, Pasteur Institute of Iran, Tehran 1316943551; ${ }^{3}$ Immunology Research Center, Tabriz University of Medical Sciences, Tabriz 5166614731;

${ }^{4}$ Department of General \& Vascular Surgery; ${ }^{5}$ Tuberculosis and Lung Disease Research Center;

${ }^{6}$ Department of Pathology, Imam Reza Hospital; ${ }^{7}$ Liver and Gastrointestinal Disease Research Center and Department of

General and Thoracic Surgery, Tabriz University of Medical Sciences, Tabriz 5165665811;

${ }^{8}$ Department of Medical Genetics, School of Medicine, Tehran University of Medical Sciences, Tehran 1471613151, Iran
\end{abstract}

Received May 1, 2016; Accepted August 26, 2016

DOI: $10.3892 / \mathrm{ol} .2016 .5327$

\begin{abstract}
Colorectal cancer (CRC) is one of the most common malignancies, and the third leading cause of cancer mortality worldwide. Timely detection of CRC in patients with earlier stages provides the highest rate of survival. Epigenetic alterations are important in the occurrence and progression of CRC, and represent the primary modifications of cancer cells. Therefore, detection of these alterations in CRC cases are thought to hold great promise as diagnostic biomarkers. It has been shown that the SEPT9 and NTRK3 genes are aberrantly methylated and their detection can be used as biomarkers for early diagnosis of CRC. The present study analyzed promoter methylation status of these genes in CRC patients. Genomic DNA was extracted from $45 \mathrm{CRC}$ and paired adjacent healthy tissues and undergone bisulfite conversion, and the methylation status of NTRK3 and SEPT9 were defined using the MS-HRM assay. Our results showed that there are statistically significant differences in methylation status of NTRK3 and specially SEPT9 between CRC and adjacent normal tissues
\end{abstract}

Correspondence to: Dr Ebrahim Sakhinia, Department of Bioechemistry and Clinical Laboratory, Division of Medical Genetics, Faculty of Medicine, Tabriz University of Medical Sciences, Golgasht Street, Tabriz 5165665811, Iran

E-mail: esakhinia@yahoo.co.uk

Dr Ladan Teimoori-Toolabi, Department of Molecular Medicine, Pasteur Institute of Iran, 69 Pasteur Street, Tehran 1316943551, Iran E-mail:1teimoori@pasteur.ac.ir

Key words: colorectal cancer, NTRK3, SEPT9, methylation, biomarker
$(\mathrm{P}<0.001)$. High sensitivity and specificity for a specific location in SEPT9 gene promoter as a diagnostic biomarker was observed. SEPT9 promoter hypermethylation may serve as a promising biomarker for the detection of CRC development. However, to validate the biomarker potential of NTRK3 there is a requirement for further investigation.

\section{Introduction}

Colorectal cancer (CRC) is one of the most common malignancies worldwide, and the second cause of cancer related deaths in developed countries $(1,2)$. CRC is the 3rd and the 4th commonly diagnosed cancer in Iranian men and women, respectively (3). The lack of clinical manifestations in CRC patients until the late stages of cancer is a common disease characteristic, which results in poor prognosis and high mortality. The process of carcinogenesis in primary adenomas, which are precursor lesions of colon cancer that eventually develop into colorectal carcinomas, is slow, and is a cause of the late diagnosis (4). Eighty percent of early-diagnosed patients are referred for tissue resection and are eventually cured (5). In order to reduce the morbidity and mortality of the disease, early diagnosis and treatment of CRC appears to be of critical importance, since there is a large preclinical asymptomatic stage in CRC patients (6).

There are several CRC screening methods, such as fecal occult blood testing (FOBT), barium enema, flexible sigmoidoscopy and colonoscopy. FOBT and colonoscopy are commonly used clinically; however, they have some technical restrictions and disadvantages (7). FOBT, while a simple method in practice, does not have high sensitivity and specificity. Considering that colonoscopy is the 'gold standard' method for CRC screening, its invasiveness nature and complicated required preparation procedure make patients 
reluctant to choose it as an acceptable screening method (7). Therefore, developing new and useful screening methods is a high priority (8).

Sporadic CRC occurrence is due to accumulation of genetic and epigenetic changes, which cause normal epithelial cells to transform into the adenocarcinoma cells (9). There is increasing evidence that widespread epigenetic alterations are the key features of most of cancer types $(10,11)$, and these changes may be important in the pathogenesis of CRC. Aberrant DNA methylation is one of the best known and well-defined epigenetic changes in tumors, and is a frequent mechanism for inappropriate gene silencing among tumor suppressor genes (12-14). DNA methylation is of particular interest, as it occurs in the primary stages of carcinogenesis, and hence, can be used as a marker for early detection of CRC (15).

Septin 9 (SEPT9) is a member of the septin gene family, which are highly conserved and encode GTP-binding proteins. Septins are multidomain proteins which together form filamentous structures that form part of cytoskeleton $(16,17)$. Furthermore, septins belong to P-loop GTPases superclass and were first identified in yeast as key genes in cell division (18). These proteins have prominent roles in multiple cellular processes, including cell membrane rigidity, establishment of separate cellular domains by creating membrane diffusion barriers, providing scaffold for localization of proteins to certain subcellular regions and determination of cell polarity $(16,18,19)$. The precise mechanism of SEPT9 molecular function in colon cancer pathogenesis has not yet been clearly described (20), however, several studies suggest possible roles in different malignancies, including leukemia (21), breast and ovarian cancer (22-24), brain tumors (25) and CRC (19,26-28).

The methylation status of the SEPT9 gene has been examined previously in CRC patients, as well as cases with precancerous lesions including adenomas in several studies (29,30). In a recent study conducted by Ahmed et al (31), a methylation panel including the SEPT9 gene was analyzed in CRC patients, and concluded that SEPT9 promoter methylation is a promising biomarker with the ability to discriminate CRC tissues as well as adenomas, from normal mucosa.

The $N T R K$ neurotrophin receptor family includes $N T R K 1$ (TrkA),NTRK2 (TrkB) and NTRK3 (TrkC), which, in conjunction with their ligands ( $N G F, B D N F$ and $N T 4 / 5, N T-3$,respectively) are important in development of the nervous system (32). It has been demonstrated previously that NTRKs have oncogenic effects in some cancer types, such as breast cancer and liver cancer (33). Recent studies have demonstrated that NTRK1 and NTRK3 may be dependent receptors, which depend on availability of their ligands to select their specific cell signals; these receptors are defined as having the ability to induce opposite effects in the presence or absence of their ligands $(34,35)$. The availability of the ligand leads to the transduction of a positive cellular survival or differentiation signal, whereas the induction of apoptosis is a result of the absence of ligand (36). Observations which have demonstrated NTRK3 is a beneficial prognostic factor in certain cancers, including melanoma and medulloblastomas, indirectly support that NTRK3 has a dependence receptor role and is a conditional tumor suppressor gene $(37,38)$. Therefore, these findings suggest that NTRK3 may act as a conditional tumor suppressor gene in CRC.
Specific somatic missense mutations in NTRK3, which probably inhibit its function, have been identified in colorectal cancer, as well as breast, lung, and pancreatic cancers $(39,40)$. Considering the possibility of NTRK3 as a CRC tumor suppressor gene, based on the discovery of its mutant and methylated forms in CRC, Luo et al (41) conducted a study in order to define the effect of aberrant methylation on NTRK3 expression, and also to define whether NTRK3 has oncogenic or tumor suppressor functions in CRC cell lines. The authors concluded that aberrant methylation of NTRK3 is prevalent in CRC and adenomas that consequently silences its expression, which suggests its tumor suppressor role. The results exhibited NTRK3's function as a dependent receptor which means that binding its ligand, NT-3, it can induce proliferation while the absence of NT-3 leads to NTRK3-mediated apoptosis. Overall, those findings suggested $N T R K 3$ as a novel conditional tumor suppressor gene in CRC.

The present study aimed to analyze the methylation status of SEPTS and NTRK3 gene promoters in order to examine their ability to differentiate CRC tissues from normal mucosa, and to assess the validity of NTRK3 as a methylation marker in clinical CRC samples.

\section{Materials and methods}

Study design. The present cross-sectional study was undertaken as a collaboration between the Immunology Research Center of Tabriz University of Medical Sciences, Imam Reza Hospital (Tabriz, Iran), Amiralmomenin Hospital (Tabriz, Iran) and Pasteur Institute of Tehran. Written informed consent was obtained from all patients participating in this study. The ethical protocol of the study was proved by the Ethical Committee of Tabriz University of Medical Sciences. A scheme of the study design is presented in Fig. 1.

Study population. Participants in this study were Iranians with the same ethnicity and geographical residency. Tumor and matched tumor-free margin samples were obtained from 45 colorectal cancer patients during surgery, which was a part of the routine treatment of patients. All patients were precisely identified as CRC patients on the basis of clinicopathological findings, all were candidates for cancer surgery, and underwent appropriate surgery at Imam Reza Hospital and Amiralmomenin Hospital, between 2014 and 2015. All the samples were referred to the laboratory under certain conditions with the complete patient information including clinicopathological and demographic data. The patients comprised of 19 males (42.2\%) and 26 females (57.8\%). None of the patients were undergone preoperative chemotherapy and/or radiotherapy and have no other malignancies. Tissue samples were separated into two distinct 45 tumor samples and 45 margin samples, which had been validated according to the pathological analysis.

Samples collection. Fresh tumor tissue and tumor-free margin tissue samples were collected during surgery in the Imam Reza Hospital, Tabriz and Amiralmomenin Hospital. Following resection, the tissue samples were immediately snap-frozen in liquid nitrogen and stored at $-80^{\circ} \mathrm{C}$ in the laboratory until further sample processing. 


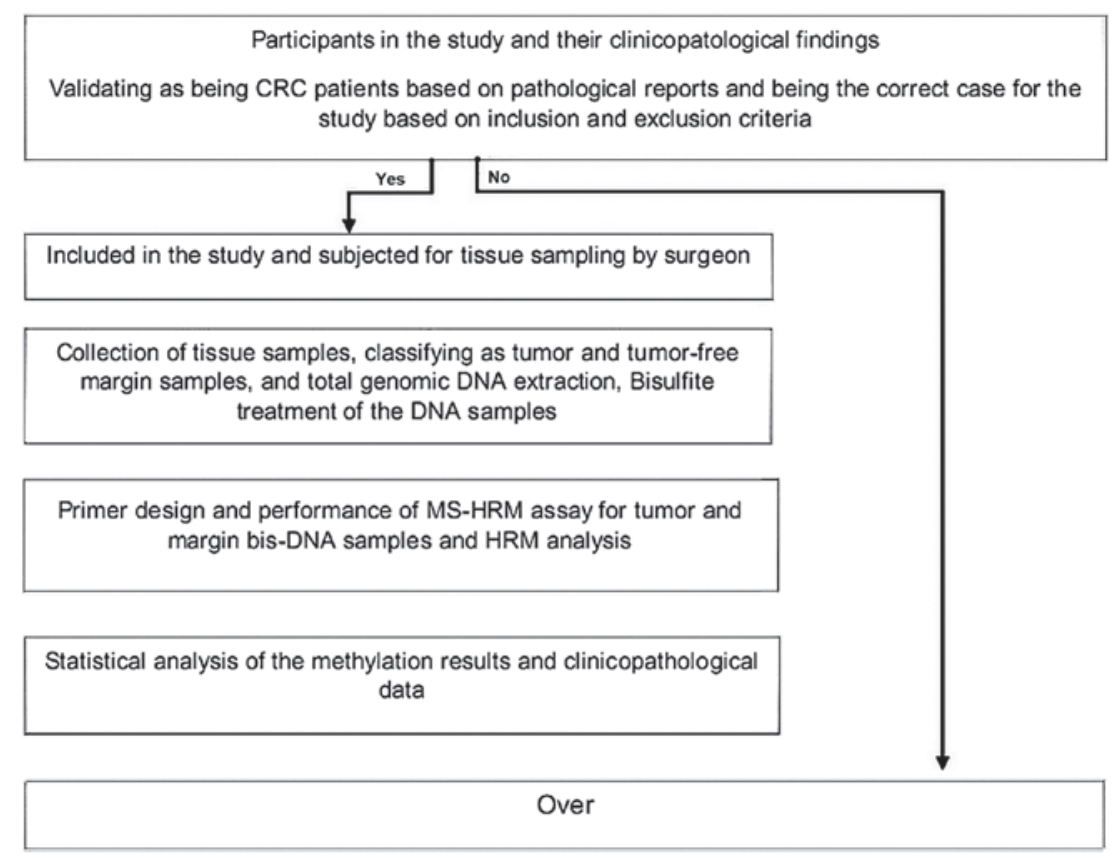

Figure 1. Schematic of the study design.

DNA extraction and sodium bisulfite modification. Total genomic DNA was extracted from tissue samples using CinnaPure-DNA kit (Cinna Colon, Iran) according to the manufacture's protocol. DNA concentrations were measured using a NanoDrop spectrophotometer, and then stored at $-20^{\circ} \mathrm{C}$ until the next step. Extracted DNA samples were excluded from the further analysis if the final concentration was $<100 \mathrm{ng} / \mu \mathrm{l}$, or the A260/A280 ratio was outside the range of 1.7-1.9. In the next step, total genomic DNA samples underwent sodium bisulfite conversion using a EZ DNA methylation-Gold kit (Zymo Research Corp. Irvine, CA, USA), according to the instructions provided by the company. The modified DNA samples were stored immediately at $-20^{\circ} \mathrm{C}$.

Methylation specific-high resolution melting (MS-HRM). HRM primer pairs were designed for specific GC rich islands in promoter sequences of each gene according to the HRM primer design guidelines (Table I). Two specific locations were analyzed within the promoter region of SEPT9 gene, and one location within the promoter region of NTRK3 gene by MS-HRM assay. For each reaction, $2 \mu \mathrm{l}$ of bis-DNA template was added to $10 \mu \mathrm{l}$ of master mix (SYBR Premix Ex Taq ${ }^{\mathrm{TM}}$ II), and $2 \mu \mathrm{l}$ of specific primer pairs with $6 \mu \mathrm{l}$ double distilled water, then placed in Real Time PCR (Applied bio system, step one plus) with the following conditions: initial denaturation at $95^{\circ} \mathrm{C}$ for $30 \mathrm{sec}$; and then 40 cycles at $95^{\circ} \mathrm{C}$ of denaturation for $5 \mathrm{sec}$, appropriate annealing temperature for each primer set (Table I) for $30 \mathrm{sec}$, and extension at $72^{\circ} \mathrm{C}$ for $30 \mathrm{sec}$. HRM analysis was done at a temperature range from $60^{\circ} \mathrm{C}$ to $95^{\circ} \mathrm{C}$ with the ramp rate of $0.3^{\circ} \mathrm{C} / 15 \mathrm{sec}$. The standard curves were included in each assay with DNA samples with known methylation ratios and then used to deduce the methylation ratio of each unknown sample. Using the HRM v.2.2 software (Applied Biosystems, Thermofisher Scientific, Waltham, MA, USA), melting curves were normalized relative to two normalization regions before and after the major decrease of fluorescence indicating the melting region of the PCR product. The output plots were in the shape of normalized melting curves. Considering the standard curves $(0,25,50,75$, and $100 \%)$, HRM data for each unknown sample were classified into different ranges of methylation by three independent observers.

Statistical analysis. The analyzed data were found not to be normally distributed, therefore, nonparametric tests were used. Statistical analysis was performed in each group using the Mann-Whitney U and Kruskal-Wallis tests. The Spearman correlation coefficient test was used to analyze any correlation between clinicopathological findings of patients and gene specific methylation. Sensitivity and specificity of test were examined using ROC curve analysis. In all tests, $\mathrm{P}<0.05$ was considered to indicate a statistically significant difference. SPSS version 22 was used for all statistical analyses (SPSS Inc., Chicago, IL, USA).

\section{Results}

Clinicopathological findings of patients. The mean age of the patients was 58.28 years (range $29-83$ years), the median weight and height of patients were $71.11 \mathrm{~kg}$ (range $50-94 \mathrm{~kg}$ ) and $165.51 \mathrm{~cm}$ (range, 150-196 cm), respectively. The tumor samples comprised of all CRC stages, however, the most prevalent stage was IIB. The pathological features of samples are displayed in Table II. The mean size of tumors was $5.5 \mathrm{~cm}$ (range 3-18 cm). Only 7 out of 45 patients were smokers.

Quantification of DNA methylation by MS-HRM assay. In order to determine the methylation level of SEPT9 and NTRK3 gene promoters, the MS-HRM assay, a semi-quantitative sensitive method was used. The assay optimized by using control dilution series including $0,25,50,75$, and $100 \%$ methylation 
controls. Representative results are shown in Fig. 2. For the first location of SEPT9 gene, methylation was observed in $5 / 45(11.11 \%)$ of normal adjacent samples and 25/45 (55.55\%) of CRCs. In the second location of SEPT9 gene, methylation was observed in $18 / 45(40 \%)$ of normal adjacent samples and $42 / 45(93.33 \%)$ of CRC samples. For NTRK3 gene, the overall methylation level was high in both normal adjacent samples and CRC samples. The methylation status of the NTRK3 gene promoter in the analyzed location was observed in $43 / 45$ (95.5\%) of normal samples and 45/45 (100\%) CRC sampless, however, the mean methylation levels in tumor samples were much higher than those of normal adjacent ones.

The median methylation levels of SEPT9 first location, SEPT9 sec location and NTRK3 in tumor samples was $24.16 \%$ (range 0 to $100 \%$ ), $60.27 \%$ (range 0 to $100 \%$ ), and $70.83 \%$ (range 25 to $100 \%$ ) respectively, and in adjacent normal tissue was $3.61 \%$ (range 0 to $75 \%$ ), $11.38 \%$ (range 0 to $75 \%$ ), and $40 \%$ (range 0 to $75 \%$ ) respectively. After doing statistical analysis it was shown that the methylation levels of SEPT9 gene in both locations and NTRK3 gene between tumor and matched normal adjacent tissue was significantly different $(\mathrm{P}<0.001$; $\mathrm{U}$ Mann-Whitney test). Interestingly there was not any correlation between clinical and pathological features of patients with methylation levels of SEPT9 gene in both locations and $N T R K 3$ gene, except for the first location of SEPT9, which was in correlation with primary tumor site. Methylation levels of SEPT9 gene first location were different in distinct tumor sites. Moreover, there was no significant correlation between the two analyzed locations of SEPT9 gene. Their methylation level was completely independent of each other.

In order to assess the applicability of SEPT9 and NTRK3 methylation as diagnostic biomarkers for CRC, the sensitivity and specificity of tests were analyzed using receiver operating characteristic (ROC) curve analysis. As shown in Table III and Fig. 3, acceptable sensitivity and specificity for SEPT9 and NTRK3 were resulted. When the cutoff of SEPT9 sec location methylation percentage was 31.25 , the sensitivity, specificity, PPV, NPV, and accuracy were 84.40, 99, 90.36, 98.27, and $87.77 \%$ respectively. The results showed that the second location of SEPT9 gene methylation could be better diagnostic marker for discriminating CRC tissues from matched normal adjacent with high accuracy. Likewise, high percentages for these parameters indicating diagnostic ability of NTRK3 and SEPT9 first location were also observed (Table III).

\section{Discussion}

The aberrant methylation in the promoter regions of genes is a prevalent event in a number of cancers including CRC (42). There are several methods to identify the methylation status of genomic DNA in specific sites; of those, MS-HRM is a highly sensitive semi-quantitative method, which can detect methylation level of specific region of bis-DNA precisely.

The MS-HRM assay was performed in order to identify the methylation status of $S E P T 9$ and NTRK3 gene promoters. The methylation levels of SEPT9 and NTRK3 genes in CRC were high compared with matched normal tissue $(\mathrm{P}<0.001)$. There was not any significant association between clinical features and pathological findings of patients and hyper-methylation of analyzed genes in this study. The results of the 
Table II. Clinicopathological findings of patients and their correlations with SEPT9 and NTRK3 methylation.

\begin{tabular}{|c|c|c|c|c|}
\hline Clinicopathological features & Frequency & $\begin{array}{l}\text { SEPT9 methylation } \\
\text { (first location) } \\
\text { P-value }\end{array}$ & $\begin{array}{l}\text { SEPT9 methylation } \\
\text { (second location) } \\
\text { P-value }\end{array}$ & $\begin{array}{l}\text { NTRK3 } \\
\text { methylation } \\
\text { P-value }\end{array}$ \\
\hline Age & & 0.31 & 0.17 & 0.18 \\
\hline$<50$ & 8 & & & \\
\hline$>50$ & 37 & & & \\
\hline Gender & & 0.76 & 0.73 & 0.60 \\
\hline Male & 19 & & & \\
\hline Female & 25 & & & \\
\hline Tumor location & & 0.04 & 0.62 & 0.38 \\
\hline Right colon & 12 & & & \\
\hline Transverse colon & 4 & & & \\
\hline Left colon & 5 & & & \\
\hline Sigmoid colon & 12 & & & \\
\hline Cecal & 3 & & & \\
\hline Rectosigmoid & 8 & & & \\
\hline Tumor size $(\mathrm{cm})$ & & 0.51 & 0.34 & 0.06 \\
\hline$<5$ & 25 & & & \\
\hline$>5$ & 20 & & & \\
\hline Tumor grade & & 0.27 & 0.29 & 0.97 \\
\hline G1 & 20 & & & \\
\hline G2 & 23 & & & \\
\hline G3 & 2 & & & \\
\hline Tumor stage & & 0.61 & 0.81 & 0.11 \\
\hline Stage I & 8 & & & \\
\hline Stage II & 17 & & & \\
\hline Stage III & 14 & & & \\
\hline Stage IV & 6 & & & \\
\hline Smoking & & 0.73 & 0.63 & 0.87 \\
\hline No & 38 & & & \\
\hline Yes & 7 & & & \\
\hline Pre-operative hemoglobin (g/dl) & & 0.41 & 0.38 & 0.41 \\
\hline$<12$ & 26 & & & \\
\hline$>12$ & 19 & & & \\
\hline
\end{tabular}

Table III. Diagnostic performance of SEPT9 and NTRK3 methylation.

\begin{tabular}{lccccccc}
\hline Gene & AUC $(95 \% \mathrm{CI})$ & $\begin{array}{c}\text { Cutoff } \\
\text { value }(\%)^{\mathrm{a}}\end{array}$ & $\begin{array}{c}\text { Sensitivity } \\
(\%)\end{array}$ & $\begin{array}{c}\text { Specificity } \\
(\%)\end{array}$ & $\begin{array}{c}\text { PPV } \\
(\%)\end{array}$ & $\begin{array}{c}\text { NPV } \\
(\%)\end{array}$ & $\begin{array}{c}\text { Accuracy } \\
(\%)\end{array}$ \\
\hline SEPT9 (first location) & $0.732(0.626-0.839)$ & 6.25 & 55.6 & 99 & 85.53 & 95.29 & 72.22 \\
SEPT9 (second location) & $0.902(0.835-0.970)$ & 31.25 & 84.40 & 99 & 90.36 & 98.27 & 87.77 \\
NTRK3 & $0.850(0.771-0.929)$ & 56.25 & 77.80 & 86.7 & 39.39 & 97.223 & 66.66 \\
\hline
\end{tabular}

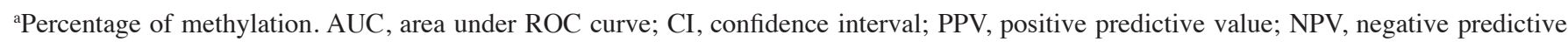
value.

present study demonstrated that the first and second studied locations of SEPT9 promoter region were not associated with age, gender, TNM stage, and grade of tumor, while the first location was just associated with tumor location. Similarly, NTRK3 methylation was not associated with such clinical and pathological parameters. Previous studies have reported that 

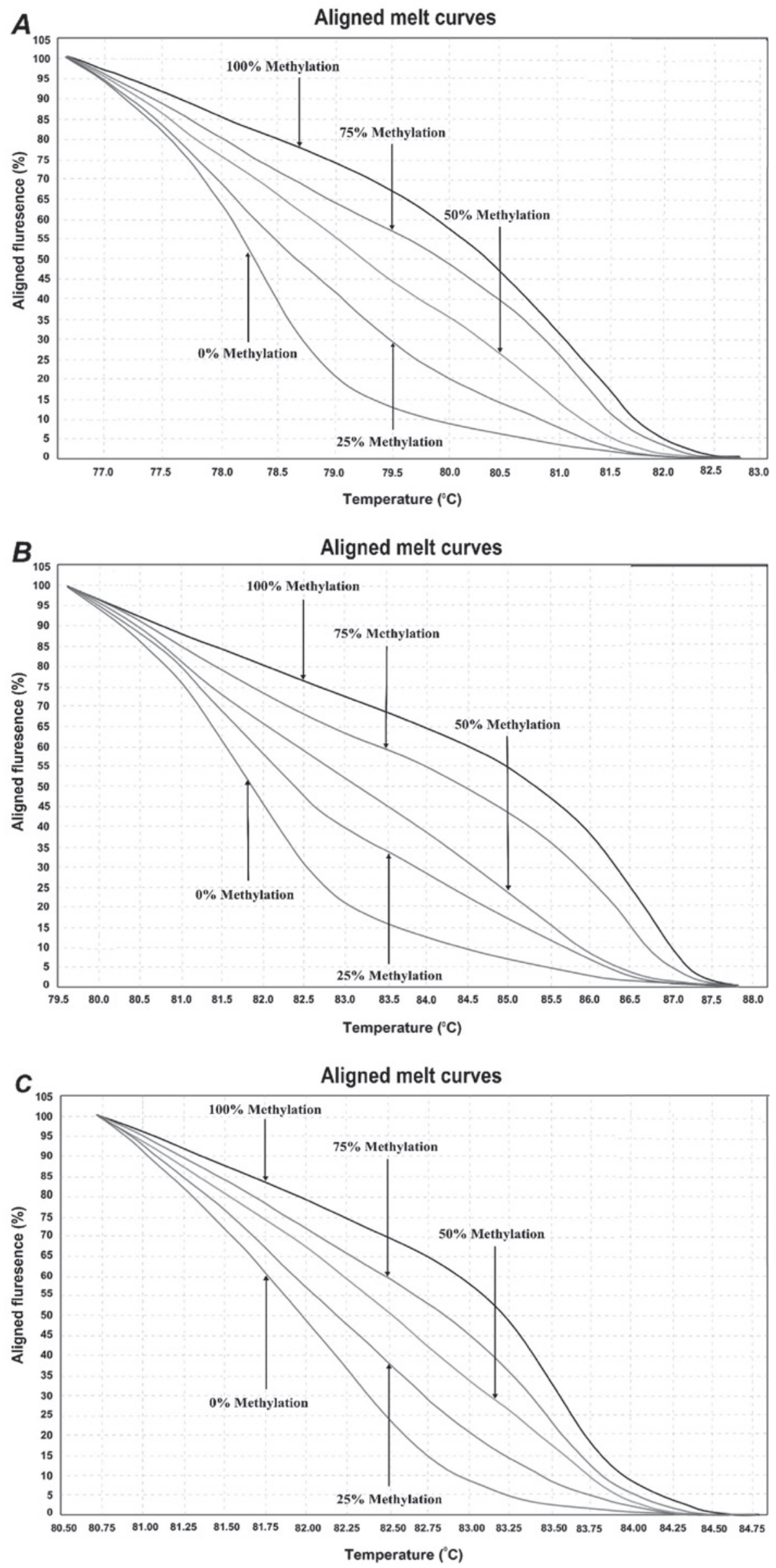

Figure 2. HRM aligned melt curves for three analyzed locations. (A) Control curves for SEPT9 gene 1st location. (B) Control curves for SEPT9 gene 2nd location. (C) Control curves for NTRK3 gene. 


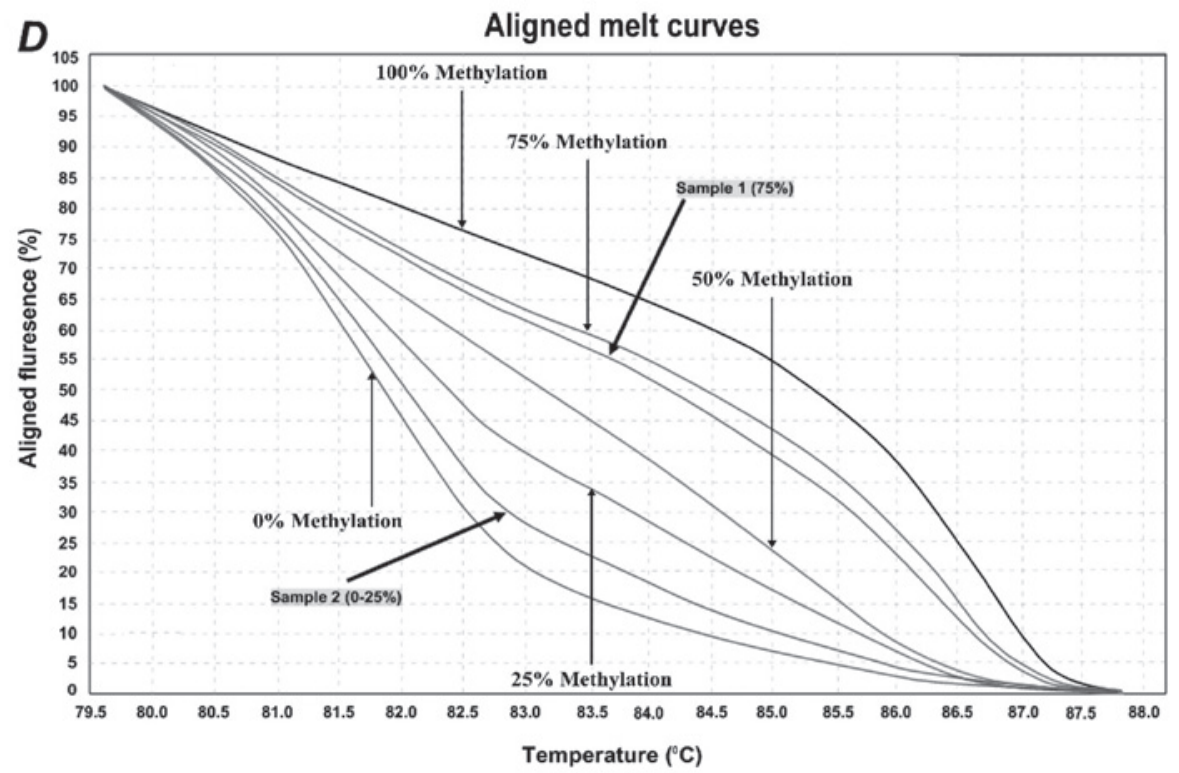

Figure 2. Continued. (D) Control curves and two sample curves for 2nd analyzed region of SEPT9 gene.

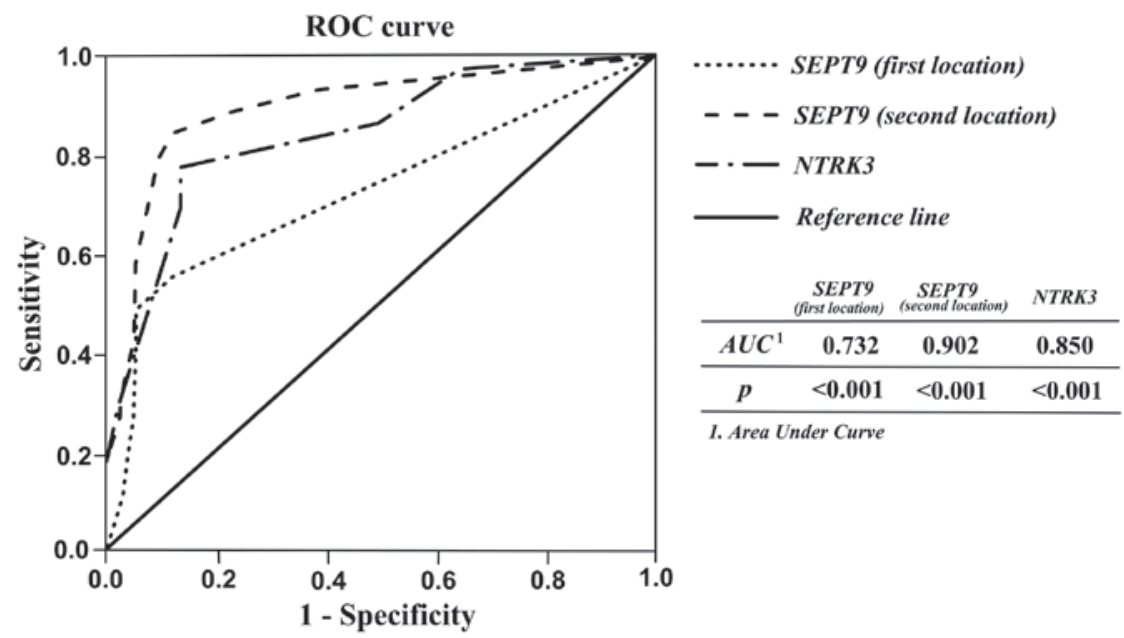

Figure 3. Receiver operating characteristic (ROC) curve analysis of SEPT9 and NTRK3 methylation using MS-HRM assay for discriminating CRC and matched adjacent normal samples.

the proportion of methylated SEPT9 genes augmented with the progression of CRC $(30,42)$, whereas our results demonstrate that this proportion of SEPT9 was similar between different stages and tumor grades of CRC cases. These results are in agreement with the results of other similar studies such as Su et al (43). However, these findings may be biased due to the small number of cases included in the study. Statistical analysis indicated that there is no association between methylation level of first and second location of SEPT9 gene, which suggests that their methylation process is independent of each other, however, the overall methylation in either tumor or normal matched adjacent tissue was higher in the second location in comparison to the first location, which may be due to the importance of this location in methylation-mediated silencing of SEPT9. In addition, the sensitivity and specificity of the second analyzed location for detection of CRC tissues form normal ones was higher than the first location. This finding suggests that this location may be more significant in
SEPT9 hypermethylation and the development of CRC, and can detect tumor tissues more precisely then first location. In an study established by Wassekort et al (44) it has been shown that hypermethylation in a specific $\mathrm{CpG}$ island of SEPT9 promoter (including our studied locations) is probably an early event in adenocarcinoma progression. Furthermore, Wassekort et al (44) have proved that there is a direct link between this region and the region cross-examined by EpiproColon test that detects methylation of SEPT9 in cell free DNA. Our results, in concordance with the published data, supports that SEPT9 methylation in this $\mathrm{CpG}$ island can be a useful biomarker in CRC diagnosis. Tóth et al (20) analyzed SEPT9 methylation in both tissue and plasma of healthy, adenoma and CRC cases quantitatively, and detected methylated SEPT9 in all tissue samples at different levels regardless of the group. Methylated SEPT9 levels in CRC and adenoma tissue samples were not significantly different; however, its levels in healthy tissue samples were much lower and considerably distinct from 
either adenoma or CRC (20). Overall, our findings supported previous studies for $S E P T 9$ gene being a promising marker for detection of CRC.

The NTRK3 gene has been recently demonstrated to become hypermethylated and silenced in CRC cell lines, which suggests its role as a tumor suppressor gene in colorectal cancer (41). The present study analyzed NTRK3 promoter methylation in order to determine whether it can act as a biomarker in diagnosis of CRC or not. Our results showed that the overall mean of methylation level in either normal tumor free tissue or CRC tumor tissue samples was high in which there were just two samples with $0 \%$ methylation. Although our results are similar to those of Luo et al (41) and obviously NTRK3 promoter methylation is able to discriminate the tumoral samples from normal tumor free samples with acceptable sensitivity and specificity, however, its high level methylation in tumor adjacent tissue suggests that it may start methylation process far before the appearance of any pathological features in cancerous cells. However, this hypothesis should indeed be further analyzed with samples in very initial stages of carcinogenesis.

In conclusion, based on our findings, SEPT9 methylation can be used as a diagnostic marker independent of different clinicopathological features of CRC patients. In particular, the second location is a promising candidate, considering its high sensitivity and specificity and also the accuracy of the test. For NTRK3 gene, we suggest further analysis with large sample size and specially samples in very initial stages of colorectal carcinogenesis in order to define its potential as a diagnostic biomarker in CRC.

\section{References}

1. Perez-Carbonell L, Balaguer F, Toiyama Y, Egoavil C, Rojas E, Guarinos C, Andreu M, Llor X, Castells A, Jover R, et al: IGFBP3 methylation is a novel diagnostic and predictive biomarker in colorectal cancer. PLoS One 9: e104285, 2014.

2. Carmona FJ, Azuara D, Berenguer-Llergo A, Fernández AF, Biondo S, de Oca J, Rodriguez-Moranta F, Salazar R, Villanueva A, Fraga MF, et al: DNA methylation biomarkers for noninvasive diagnosis of colorectal cancer. Cancer Prev Res (Phila) 6: 656-665, 2013

3. Mahmodlou R, Mohammadi P and Sepehrvand N: Colorectal cancer in northwestern Iran. ISRN Gastroenterol 2012: 968560, 2012.

4. Wang X, Kuang YY and Hu XT: Advances in epigenetic biomarker research in colorectal cancer. World J Gastroenterol 20: 4276-4287, 2014.

5. Smith RA, Cokkinides V and Eyre HJ: American Cancer Society guidelines for the early detection of cancer, 2006. CA Cancer J Clin 56: 11-25; quiz 49-50, 2006.

6. Siegel R, Naishadham D and Jemal A: Cancer statistics, 2012. CA Cancer J Clin 62: 10-29, 2012.

7. Jenkinson F and Steele R: Colorectal cancer screening-methodology. Surgeon 8: 164-171, 2010.

8. Lu H, Huang S, Zhang X, Wang D, Zhang X, Yuan X, Zhang Q and Huang Z: DNA methylation analysis of SFRP2, GATA4/5, NDRG4 and VIM for the detection of colorectal cancer in fecal DNA. Oncol Lett 8: 1751-1756, 2014.

9. Grady WM and Carethers JM: Genomic and epigenetic instability in colorectal cancer pathogenesis. Gastroenterology 135: 1079-1099, 2008.

10. Timp W and Feinberg AP: Cancer as a dysregulated epigenome allowing cellular growth advantage at the expense of the host. Nat Rev Cancer 13: 497-510, 2013.

11. Baylin SB and Jones PA: A decade of exploring the cancer epigenome-biological and translational implications. Nat Rev Cancer 11: 726-734, 2011.

12. Kondo Y and Issa JP: Epigenetic changes in colorectal cancer. Cancer Metastasis Rev 23: 29-39, 2004.
13. Ushijima T: Detection and interpretation of altered methylation patterns in cancer cells. Nat Rev Cancer 5: 223-231, 2005.

14. Petko Z, Ghiassi M, Shuber A, Gorham J, Smalley W, Washington MK, Schultenover S, Gautam S, Markowitz SD and Grady WM: Aberrantly methylated CDKN2A, MGMT, and MLH1 in colon polyps and in fecal DNA from patients with colorectal polyps. Clin Cancer Res 11: 1203-1209, 2005.

15. Draht MX, Riedl RR, Niessen H, Carvalho B, Meijer GA, Herman JG, van Engeland M, Melotte V and Smits KM: Promoter $\mathrm{CpG}$ island methylation markers in colorectal cancer: The road ahead. Epigenomics 4: 179-194, 2012.

16. Estey MP, Kim MS and Trimble WS: Septins. Curr Biol 21: R384-R387, 2011.

17. Sandrock K, Bartsch I, Bläser S, Busse A, Busse E and Zieger B: Characterization of human septin interactions. Biol Chem 392: 751-761, 2011.

18. Hall PA and Russell S: The pathobiology of the septin gene family. J Pathol 204: 489-505, 2004.

19. Wasserkort R, Kalmar A, Valcz G, Spisak S, Krispin M, Toth K, Tulassay Z, Sledziewski AZ and Molnar B: Aberrant septin 9 DNA methylation in colorectal cancer is restricted to a single CpG island. BMC Cancer 13: 398, 2013

20. Tóth K, Wasserkort R, Sipos F, Kalmár A, Wichmann B, Leiszter K, Valcz G, Juhász M, Miheller P, Patai ÁV, et al: Detection of methylated septin 9 in tissue and plasma of colorectal patients with neoplasia and the relationship to the amount of circulating cell-free DNA. PloS One 9: e115415, 2014.

21. Kojima K, Sakai I, Hasegawa A, Niiya H, Azuma T, Matsuo Y, Fujii N, Tanimoto M and Fujita S: FLJ10849, a septin family gene, fuses MLL in a novel leukemia cell line CNLBC1 derived from chronic neutrophilic leukemia in transformation with $\mathrm{t}(4$; 11)(q21; q23). Leukemia 18: 998-1005, 2004.

22. Connolly D, Yang Z, Castaldi M, Simmons N, Oktay MH, Coniglio S, Fazzari MJ, Verdier-Pinard P and Montagna C: Septin 9 isoform expression, localization and epigenetic changes during human and mouse breast cancer progression. Breast Cancer Res 13: R76, 2011

23. Scott M, McCluggage WG, Hillan KJ, Hall PA and Russell SE: Altered patterns of transcription of the septin gene, SEPT9, in ovarian tumorigenesis. Int J Cancer 118: 1325-1329, 2006.

24. Burrows JF, Chanduloy S, McIlhatton MA, Nagar H, Yeates K, Donaghy P, Price J, Godwin AK, Johnston PG and Russell SE: Altered expression of the septin gene, SEPT9, in ovarian neoplasia. J Pathol 201: 581-588, 2003.

25. Kim DS, Hubbard SL, Peraud A, Salhia B, Sakai K and Rutka JT: Analysis of mammalian septin expression in human malignant brain tumors. Neoplasia 6: 168-178, 2004.

26. Church TR, Wandell M, Lofton-Day C, Mongin SJ, Burger M, PayneSR, Castaños-VélezE, Blumenstein BA, Rösch T, Osborn N, etal: Prospective evaluation of methylated SEPT9 in plasma for detection of asymptomatic colorectal cancer. Gut 63: 317-325, 2014.

27. Tóth K, Sipos F, Kalmár A, Patai ÁV, Wichmann B, Stoehr R, Golcher H, Schellerer V, Tulassay Z and Molnár B: Detection of methylated SEPT9 in plasma is a reliable screening method for both left- and right-sided colon cancers. PLoS One 7: e46000, 2012.

28. Tóth K, Galamb O, Spisák S, Wichmann B, Sipos F, Valcz G, Leiszter K, Molnár B and Tulassay Z: The influence of methylated septin 9 gene on RNA and protein level in colorectal cancer. Pathol Oncol Res 17: 503-509, 2011.

29. Tänzer M, Balluff B, Distler J, Hale K, Leodolter A, Röcken C, Molnar B, Schmid R, Lofton-Day C, Schuster T and Ebert MP: Performance of epigenetic markers SEPT9 and ALX4 in plasma for detection of colorectal precancerous lesions. PLoS One 5: e9061, 2010.

30. Warren JD, Xiong W, Bunker AM, Vaughn CP, Furtado LV, Roberts WL, Fang JC, Samowitz WS and Heichman KA: Septin 9 methylated DNA is a sensitive and specific blood test for colorectal cancer. BMC Med 9: 133, 2011.

31. Ahmed D, Danielsen SA, Aagesen TH, Bretthauer M, Thiis-Evensen E, Hoff G, Rognum TO, Nesbakken A, Lothe RA and Lind GE: A tissue-based comparative effectiveness analysis of biomarkers for early detection of colorectal tumors. Clin Transl Gastroenterol 3: e27, 2012.

32. Luther JA and Birren SJ: Neurotrophins and target interactions in the development and regulation of sympathetic neuron electrical and synaptic properties. Auton Neurosci 151: 46-60, 2009.

33. Nakagawara A: Trk receptor tyrosine kinases: A bridge between cancer and neural development. Cancer Lett 169: 107-114, 2001. 
34. Bouzas-Rodriguez J, Cabrera JR, Delloye-Bourgeois C, Ichim G, Delcros JG, Raquin MA, Rousseau R, Combaret V, Bénard J, Tauszig-Delamasure S and Mehlen P: Neurotrophin-3 production promotes human neuroblastoma cell survival by inhibiting TrkC-induced apoptosis. J Clin Invest 120: 850-858, 2010.

35. Nikoletopoulou V, Lickert H, Frade JM, Rencurel C, Giallonardo P, Zhang L, Bibel M and Barde YA: Neurotrophin receptors TrkA and TrkC cause neuronal death whereas TrkB does not. Nature 467: 59-63, 2010.

36. Goldschneider D and Mehlen P: Dependence receptors: A new paradigm in cell signaling and cancer therapy. Oncogene 29: 1865-1882, 2010.

37. Xu X, Tahan SR, Pasha TL and Zhang PJ: Expression of neurotrophin receptor Trk-C in nevi and melanomas. J Cutan Pathol 30: 318-322, 2003.

38. Segal RA, Goumnerova LC, Kwon YK, Stiles CD and Pomeroy SL: Expression of the neurotrophin receptor TrkC is linked to a favorable outcome in medulloblastoma. Proc Natl Acad Sci USA 91: 12867-12871, 1994.

39. Bardelli A, Parsons DW, Silliman N, Ptak J, Szabo S, Saha S, Markowitz S, Willson JK, Parmigiani G, Kinzler KW, et al: Mutational analysis of the tyrosine kinome in colorectal cancers. Science 300: 949, 2003.
40. Wood LD, Calhoun ES, Silliman N, Ptak J, Szabo S, Powell SM, Riggins GJ, Wang TL, Yan H, Gazdar A, et al: Somatic mutations of GUCY2F, EPHA3, and NTRK3 in human cancers. Hum Mutat 27: 1060-1061, 2006.

41. Luo Y, Kaz AM, Kanngurn S, Welsch P, Morris SM, Wang J, Lutterbaugh JD, Markowitz SD and Grady WM: NTRK3 is a potential tumor suppressor gene commonly inactivated by epigenetic mechanisms in colorectal cancer. PLoS Genet 9: e1003552, 2013.

42. deVos T, Tetzner R, Model F, Weiss G, Schuster M, Distler J, Steiger KV, Grützmann R, Pilarsky C, Habermann JK, et al: Circulating methylated SEPT9 DNA in plasma is a biomarker for colorectal cancer. Clinical chemistry 55: 1337-1346, 2009.

43. Su XL, Wang YF, Li SJ, Zhang F and Cui HW: High methylation of the SEPT9 gene in Chinese colorectal cancer patients. Genet Mol Res 13: 2513-2520, 2014.

44. Wasserkort R, Kalmar A, Valcz G, Spisak S, Krispin M, Toth K, Tulassay Z, Sledziewski AZ and Molnar B: Aberrant septin 9 DNA methylation in colorectal cancer is restricted to a single CpG island. BMC Cancer 13: 398, 2013. 